\title{
Vibration Control of a Lathe Tool Post Using Shape Memory Alloy
}

\author{
Senthilkumar $\mathrm{M}^{1}$, Ram Prakash $\mathrm{S}^{2}$, Naveen $\mathrm{S}^{3}$, Ramasubramaniam $\mathrm{SK}^{4}$, Prathip $\mathrm{M}^{5}$ \\ \{msk.prod@psgtech.ac.in ${ }^{1}$, srp2221997@gmail.com ${ }^{2}$, naveensrinu96@gmail.com ${ }^{3}$, vocskr@gmail.com ${ }^{4}$, \\ psgprathip2014@gmail.com ${ }^{5}$ \} \\ 1,2,3,4,5 Department of Production Engineering, PSG College of Technology, Coimbatore, India
}

\begin{abstract}
Machine tool has been used for manufacturing of various precise and adverse components which have wide engineering applications throughout the world. The use of a machine tool as a manufacturing tool is inevitable. The problem that has been faced with the machine tool is the effect of vibration which results in loss of accuracy and stability of the process. This paper aims at reducing the vibration values of lathe tool post by incorporating a control system in the form of Shape Memory Alloy-Dynamic Vibration Absorber (SMA-DVA). The LabVIEW software is used to record the acceleration, frequency and displacement plots before and after installation of DVA. The DAQ (Data AcQuisition) card serves as an interface between the LabVIEW software and Accelerometer in recording the readings and plots. The turning operation is performed in lathe without installation of DVA and is performed again after installation of DVA. The RMS value of acceleration is taken for comparison and the percentage reduction of RMS value is calculated. From the percentage reduction values, the effectiveness of the installed DVA is found out.
\end{abstract}

Keywords: Vibration control, Shape Memory Alloy, Dynamic Vibration Absorber, LabVIEW, NI-DAQ.

\section{Introduction}

Machine tool has been used for manufacturing of various precise and adverse components which have wide engineering applications throughout the world. The use of a machine tool as a manufacturing tool is inevitable. The problem that has been faced with the machine tool is the effect of vibration which results in loss of accuracy and stability of the process. The loss of accuracy and stability results in poor quality of the product being manufactured. Therefore, a suitable technique is to be implemented which could eliminate the vibrations in a machine tool and thereby increasing the accuracy of machined components. Furthermore, there is a large scope of extending this paper to minimize the size of the DVA implemented and also, in a more advanced method, this entire miniature vibration control device can be made as a part of the lathe Simulation in LabVIEW software.

The work has been categorized into four areas as follows:

i. Machine tool vibration and chatter control techniques

ii. Dynamic Vibration Absorbers- Performance and improvement

iii. Research into Shape memory alloys' properties and applications 


\section{Literature Review}

Liu and Shao (2011)[7] have studied the rail traffic noise caused by the vibration of wheel and rail. Ma et al.(2017)[5] have studied the major hindrance for achieving high quality and high production rate in machining processes. Munoa et al.,(2015)[6] have studied the chatter vibrations coming from the machine tool structure. Prasad and Prakash (2016)[1] have analyzed a correlation between vibration amplitude and tool wear when in dry turning of AISI 4140 steel using uncoated carbide insert DNMA 432 via experiments and finite element simulations. Machado and Lagoudas (2006)[8] have investigated numerically and experimentally the non-linear vibration of a shape memory alloy(SMA) passive damping vibration device, where the main elements are pseudo-elastic SMA wire. Shariat et al.(2017)[17] have studied that functionally graded shape memory alloy have the advantage of combining the functionalities of the shape memory effect and those of functionally graded structures, and also improved controllability in actuating applications. Moradi et al.,(2014)[9] have designed a tunable vibration absorber(TVA) to suppress regenerative chatter in milling. Cheung et.al (2014)[2] have proposed that a dynamic vibration absorbers are commonly designed and tuned to suppress vibration of one vibration mode of a vibrating structure even if it is multi degree-of-freedom(MDOF) or a continuous structure. Debra(1992)[3] has investigated that the successful precision engineering is the balance of robustness of the machine and how benign the environment can be made through isolation to minimize the strains caused by vibration that compromise a machine's accuracy. García Plaza and Núñez López[4] have carried out surface roughness monitoring by singular spectrum analysis of vibration signals. Machado and Lagoudas[8] have done nonlinear dynamics of a SMA passive vibration damping device. .

Senthilkumar[10] has developed active vibration absorbers for machine tools using shape memory alloys. Tavakolpour Saleh and Mailah[19] stuided on control of resonance phenomenon in flexible structures via active support. Senthilkumar at al[11] developed a shape memory alloy based actively tuned undamped mass absorber. Shariat et al[17] have presented on functionally graded shape memory alloys. Senthilkumar[12] has done an analysis of smart wing using shape memory alloy. Sriram et al[18] have developed a tuned vibration absorber using shape memory alloy. Senthilkumar et al[13] has done fault diagnosis of centrifugal pump and vibration control using shape memory alloy based ATDVA. Senthilkumar et al[14] has done a resarch on vibration control of small horizontal axis wind turbine blade with shape memory alloy. Senthilkumar et al[15] studied on tunable vibration based energy harvester using shape memory effect. Senthilkumar et al[16] have developed an electromechanical analytical model of shape memory alloy based tunable cantilevered piezoelectric energy harvester. Vasundhara et al[20] have devloepd a distributed parametric model of shape memory alloy based resonant frequency tunable cantilevered PZT energy harvester with tip mass.

From the collected research papers, the problem definitions, experimentations, resulting data from experimenting and interpretation of these journals are clearly caught on. From the content in all these collected papers-of-interest, experimentations/ researches/ analysis which are closely related to the work intended in this report are given extra care to thoroughly understand. 


\section{Problem Definition}

Based on a detailed literature survey conducted, it is clear that to proceed further in depth with the work carried out, it is important to list out the issues that are commonly faced by the people in the industry and the idea which has been put forward that with the help of an extra physical, electrical and electronic arrangements will try to minimize the problems to the best possible extent. Machine tool vibration is one of the most dangerous of all problems faced in an industry. Such vibration in any machine tool is an unavoidable cause of fatigue and ultimate failure of the machine. The vibration absorbs are often characterized based on the extent to which they can reduce the magnitude or amplitude of vibration and not completely eliminating it. The main effect of machine tool vibration on the part being machined on the machine is the increase in the roughness value of the part's surface profile. This may even sometimes seriously effect in the assembly of parts. So there will be a need for finish machining the part for improved surface finish like grinding, honing, etc. However, vibrations are inevitable in finish machining processes also. Therefore a SMA tuned vibration damper called a Dynamic Vibration Absorber (DVA) will be devised to minimize vibration to a greater extent and improve accuracy of a machining process and also to enhance its stability. Once after stating out the problems and the idea clearly, the objectives to be achieved are sort out by prioritizing the primary objective of the entire report and the sub goals set to achieve the main goal.

\section{Objectives}

This paper aims at developing a setup that when attached with the tool post of the lathe that has relative motion with the other parts of the lathe, will be effective in considerably reducing the vibrations induced in it. This setup is the Dynamic Vibration Absorber (DVA) that is nothing but a mass-spring combination. This DVA will take the lathe vibrations into itself and will start oscillating at an amplitude depending on the secondary mass $\mathrm{m} 2$ and spring stiffness K. This paper discusses the replacement of this spring in DVA with a shape memory alloy (SMA) material (NiTinol) to dampen the aforementioned vibrations experienced in lathe. This idea has been successfully tested and the vibration amplitude has reduced to the expected extent after incorporating the SMA-DVA. Primary objective of this entire report is to control vibration in a lathe by designing a suitable active vibration control device using shape memory alloy with a software to input appropriate set values of parameters continuously and to record these values.

\subsection{Specific objectives are,}

1) To perform machining operation on a standard workpiece in accord with the set values of Speed-Depth of cut combinations and perform data logging in LabVIEW.

2) To design SMA-DVA with an SMA wire (made of NiTinol) of constant diameter throughout its length with equivalent length between the 2 plates assumed appropriately.

3) To compare the vibration obtained for before and after installation of DVA and arrive at the percentage reduction of vibration amplitude achieved after installing DVA that decides its effectiveness. 


\section{Methodology}

Methodology of this work has been divided into two phases. Phase 1 of the work involves literature review, problem definition, framework and conducting experiments with LabVIEW software and accelerometer. Phase 2 of the work involves calculating various parameters for the SMA-DVA, including the current controller within LabVIEW software (instead of using a controller as a separate hardware component) and conducting experiments after the installation of DVA.

- Conducting literature review and arriving at problems definition.

- Framework of objectives that are to be accomplished.

- Deciding on a machine tool to control vibration.

- Conducting experiments with accelerometer and LabVIEW software and recording the RMS and maximum acceleration values for further study.

- Calculate the specification of the SMA material by arriving at $\mathrm{m}, \mathrm{k}$ and $\omega$ values.

- Design of control system in LabVIEW software to alter the current input for varying vibration values. The control system is made as an inbuilt software component and use of external hardware component is thus eliminated.

- Performing experiments after installation of SMA-DVA and obtaining acceleration related plots from LabVIEW software.

- Recording the RMS and maximum acceleration values for comparison.

- Calculation of percentage reduction of RMS and maximum acceleration values without DVA and after the installation of DVA.

- Interpretation of results and comparison of acceleration values using charts.

- Performing analysis to calculate the effectiveness of the designed SMA-DVA

\section{Experiments with no vibration control}

The LabVIEW 2017 software has been used. The DAQ (Data AcQuisition) card is connected with the laptop via a USB cable and the accelerometer sensor is connected to the DAQ card in the ports available. The lathe is run and the accelerometer sensor is placed on the lathe bed. Nine trials are conducted each for one combination of a factor and a level for a 3 factor 3 level experiment.

Fig 6.1 and Fig 6.2 show the complete experimental setup where accurate results of vibration can be obtained because of the involvement of software programming into the manual lathe turning operation. The accelerometer sensor is fitted onto the lathe bed by means of applying a wax layer to stick it with the bed surface. 


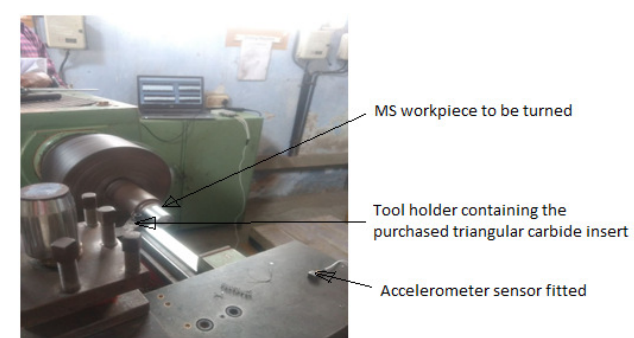

Fig 6.1. Machine running with the hardware setup

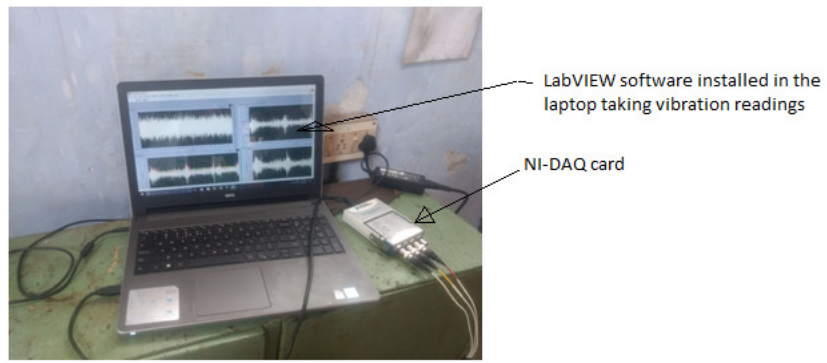

Fig 6.2. LabVIEW software recording readings

Fig 6.3 indicates the status of the software (interfaced with NI-DAQ card) taking vibration measurements at $800 \mathrm{rpm}$ and $0.3 \mathrm{~mm}$ depth of cut. For each of the 9 combinations the values are stored by starting and stopping every time and the maximum values are programmed to be updated automatically.

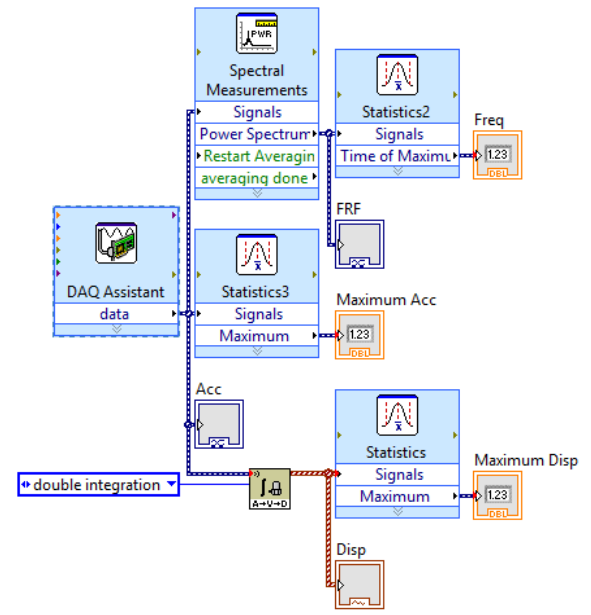

Fig 6.3. LabVIEW Program for Data Collection 


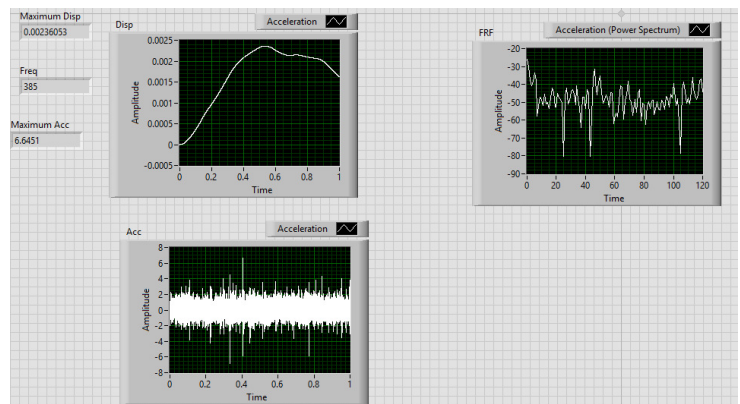

Fig .6.4 Software - Measurement and data collection for the speed 800rpm - depth of cut $0.3 \mathrm{~mm}$ combination

Fig 6.4 indicates the status of the software (interfaced with NI-DAQ card) taking vibration measurements at $800 \mathrm{rpm}$ and $0.3 \mathrm{~mm}$ depth of cut. For each of the 9 combinations the values are stored by starting and stopping every time and the maximum values are programmed to be updated automatically.

The displacement, acceleration and FRF plots shown respectively in Fig 6.5, 6.6 and 6.7 pertain to a sample combination of $360 \mathrm{rpm}$ spindle speed $-0.1 \mathrm{~mm}$ depth of cut. Fig 6.5 is the displacement graph in the acceleration domain. During the measurement period, the maximum displacement of the lathe bed is realized whose value is $0.00253992 \mathrm{~mm}$. By double integrating the graph in Fig 6.5, acceleration profile can be attained as in Fig 6.6. Obviously the acceleration reaches its maximum somewhere in the region where the displacement increases from 0 to $0.00253992 \mathrm{~mm}$.

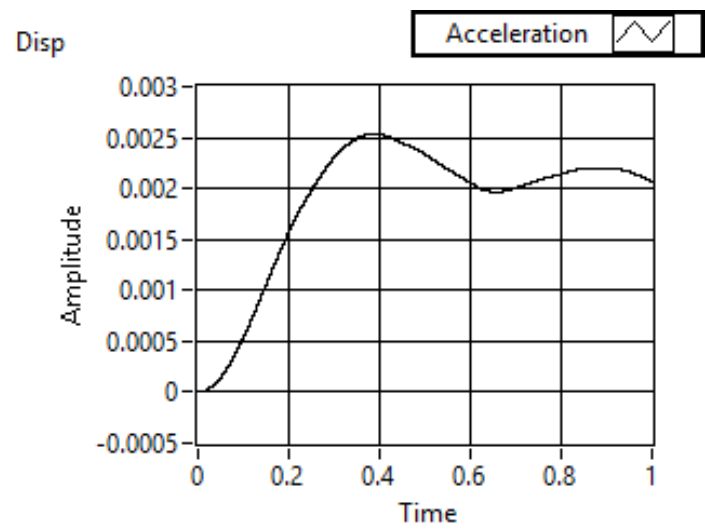

Fig 6.5. Displacement of Lathe bed in $360 \mathrm{rpm}-0.1 \mathrm{~mm}$ depth of cut 


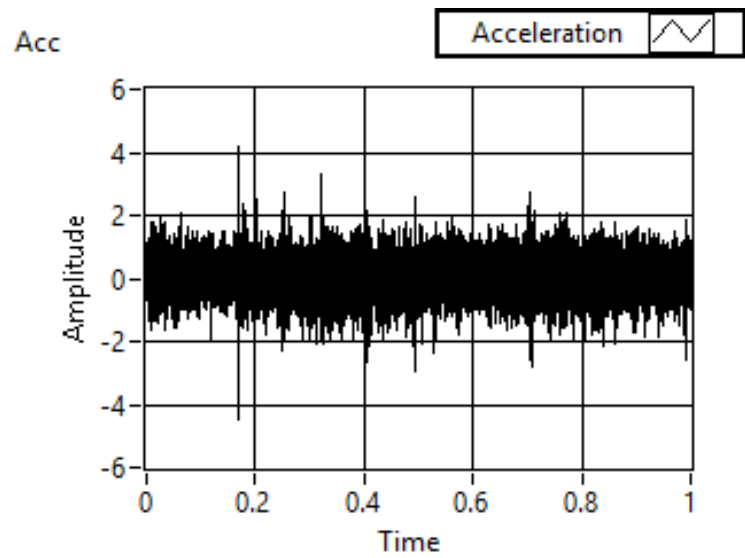

Fig 6.6. Acceleration of Lathe bed in 360rpm- $0.1 \mathrm{~mm}$ depth of cut FRF Acceleration (Power Spectrum) $\leadsto$

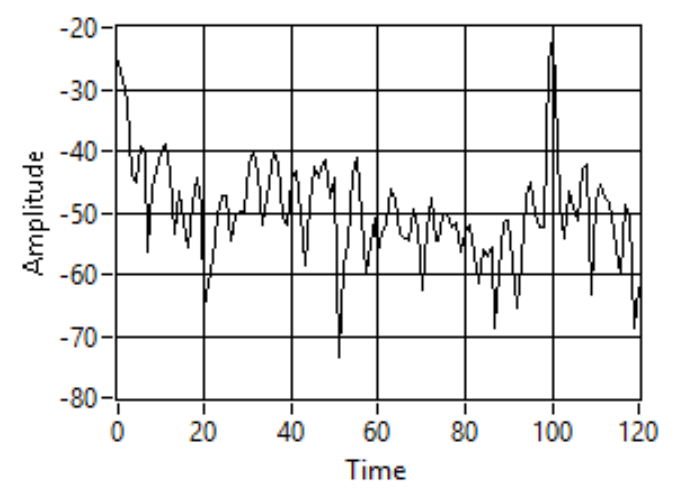

Fig 6.7. Frequency Response Function (FRF) of Lathe bed in 360rpm- $0.1 \mathrm{~mm}$ depth of cut

The FRF plot shown in Fig 6.7 gives the details about Resonance, Damping and Mode shape. Resonance is achieved at the peak points (presence of natural frequencies). The width of each peak corresponds to the amount of damping. If the width of the peak is higher, then there is a larger damping. Hence this dampening effect property of the FRF curve will be used for interpreting the reading obtained after installing SMA-DVA for comparison.

All these values are recorded in the acceleration domain and the dynamic velocity profile of the lathe bed can be easily obtained by integrating the acceleration curve or by differentiating the displacement curve at all the points.

\title{
7. Calculation and Modeling
}

\author{
Volume of the T.athe Tonl Post $=0.001785 \mathrm{~m}^{2}$ \\ Density of Cast iron $=7000 \mathrm{~kg} / \mathrm{m}^{2}$ \\ Mass $\left(\mathrm{m}_{1}\right)=7000 * 0.001785=12.495 \mathrm{~kg}$
}


$\mathrm{f}_{1}=100 \mathrm{~Hz}$, from the plots obtained using accelerometer.

$\omega_{1}=100 / 2 \pi=15.92 \mathrm{rad} / \mathrm{sec}$

$\left.\omega_{1}=\sqrt{\left(\mathrm{K}_{\mathrm{eq}}\right.} / \mathrm{m}_{1}\right)$

Therefore, $\mathrm{K}_{\mathrm{eq}}=3166.81 \mathrm{~N} / \mathrm{m}$

Assuming $\mu=0.01$,

$\mathrm{m}_{2}=\mu * \mathrm{~m}_{3}$

$\mathrm{m}_{2}=0.12495 \mathrm{~kg}$

For resonance, $\omega_{1}=\omega_{2}$

$\left.\omega_{2}=\sqrt{\left(\mathrm{K}_{2}\right.} / \mathrm{m}_{2}\right)$

Hence, $\mathrm{K}_{2}=31.680 \mathrm{~N} / \mathrm{m}$

Stiffness $(\mathrm{K})=$ AF $/ \mathrm{T}$.

Let, Length between two plates (L) $=200 \mathrm{~mm}$ (Fig 7.1)

Young's Modulus $(\mathrm{E})=25 \mathrm{GPa}$

Diameter of SMA Wire $(\mathrm{D})=0.5 \mathrm{~mm}$
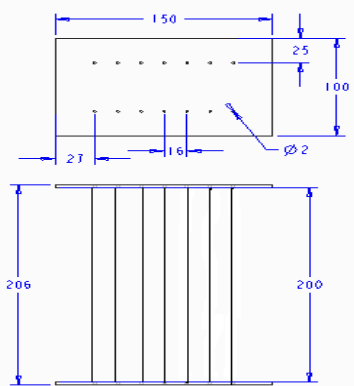

Fig 7.1: DVA design

Cross section of SMA Wire (A) $\quad=\left(\frac{\pi}{d}\right) *\left(d^{2}\right)$

Stiffness $(\mathrm{K})=\mathrm{AE} / \mathrm{L}$

$$
\mathrm{K}=2.392 \mathrm{~N} / \mathrm{m}
$$

As calculated before, for $\boldsymbol{\mu}=\mathbf{0} . \mathbf{1}, \mathrm{K}_{\mathrm{eq}}=31.68 \mathrm{~N} / \mathrm{m}$

\section{No. of Strands $(n)=14$ Strands}

$$
\mathrm{n}=\mathrm{F}_{\mathrm{fq}} / \mathrm{K}=13.24
$$

Total Length of wire required $=14 * 200 \mathrm{~mm}=2800 \mathrm{~mm}$

If 2 such identical connections are to be used in parallel, then for each connection, No. of coils for each connection $=14 / 2=7$ strands per connection (as in Fig 7.2)

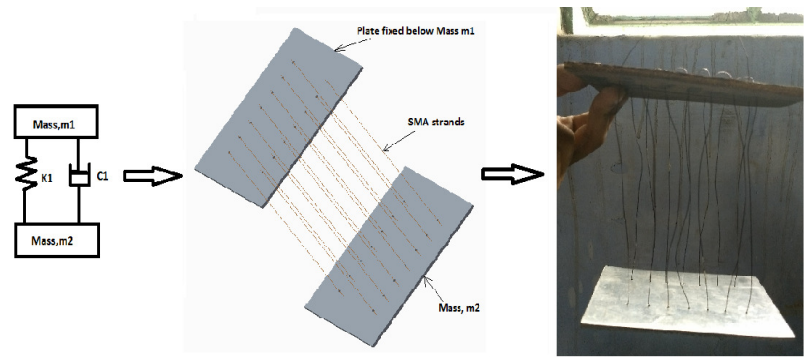

Fig 7.2: Concept, design and modeling, and fabrication of SMA-DVA

\section{Experimentation with Active Control}

Dynamic Vibration absorber has been constructed with Shape Memory Alloy wire (SMADVA) for which the specifications were found. The DVA so designed, has been installed in the Lathe Tool post in order to control the vibration. An aluminium plate of mass 125 grams has been used as the Secondary mass (m2). SMA wire has been wound between a wooden plate of negligible mass and the aluminium plate, with the distance between both the plates as

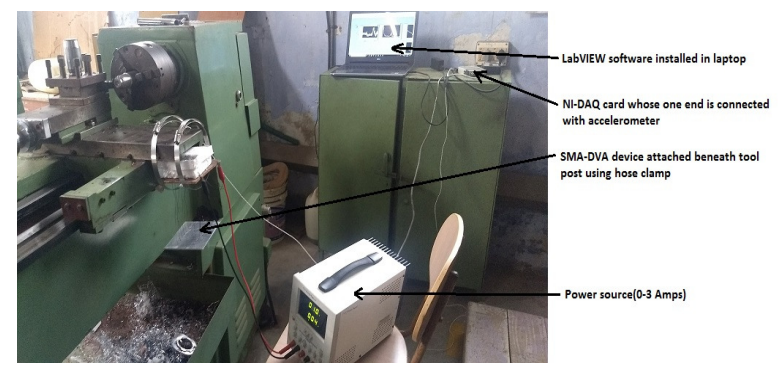


$200 \mathrm{~mm}$. The experimental setup with DVA is shown in Fig 8.1.

Fig 8.1: Experimental setup with SMA-DVA, current source and software

Piezoelectric Accelerometer is used to measure the data. As in the previous case, data has been taken only for the vibration in Z-direction. Accelerometer has been connected to the laptop by means of Data Acquisition Card (NI-DAQ Card). Block diagram has been constructed using LabVIEW and is shown in Fig 8.2.

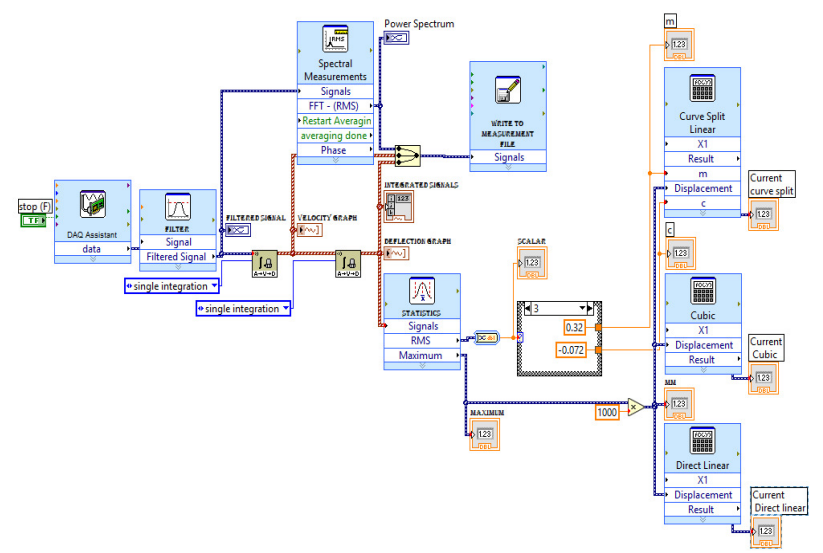

Fig 8.2: LabVIEW block diagram for measuring values with DVA and controller

Since a separate control system is not designed for cost constraint, relation between acceleration and the current value has been encoded in software itself. A linear equation has been derived using interpolation $(Y=0.2516 \mathrm{X}$ - 0.0192) between the amplitude of acceleration values (X) and the current (Y) of range 0.5 - 3 Amps (Table 8.1). Although cubic and other higher order polynomial interpolations would yield a more accurate relation between the variables and give more close control, they involve more complex algorithms and would consume time.

Table 1. Current values to be set for the 9 acceleration values

\begin{tabular}{|c|c|c|c|c|c|c|c|c|c|}
\hline Acceleration (m/s $\left.\mathbf{s}^{2}\right)$ & 2.063 & 3.923 & 4.195 & 4.538 & 5.171 & 5.409 & 6.04 & 6.645 & 11.998 \\
\hline $\begin{array}{c}\text { Current setting } \\
\text { (Amp) }\end{array}$ & 0.5 & 0.968 & 1.036 & 1.123 & 1.282 & 1.342 & 1.501 & 1.653 & 3 \\
\hline
\end{tabular}



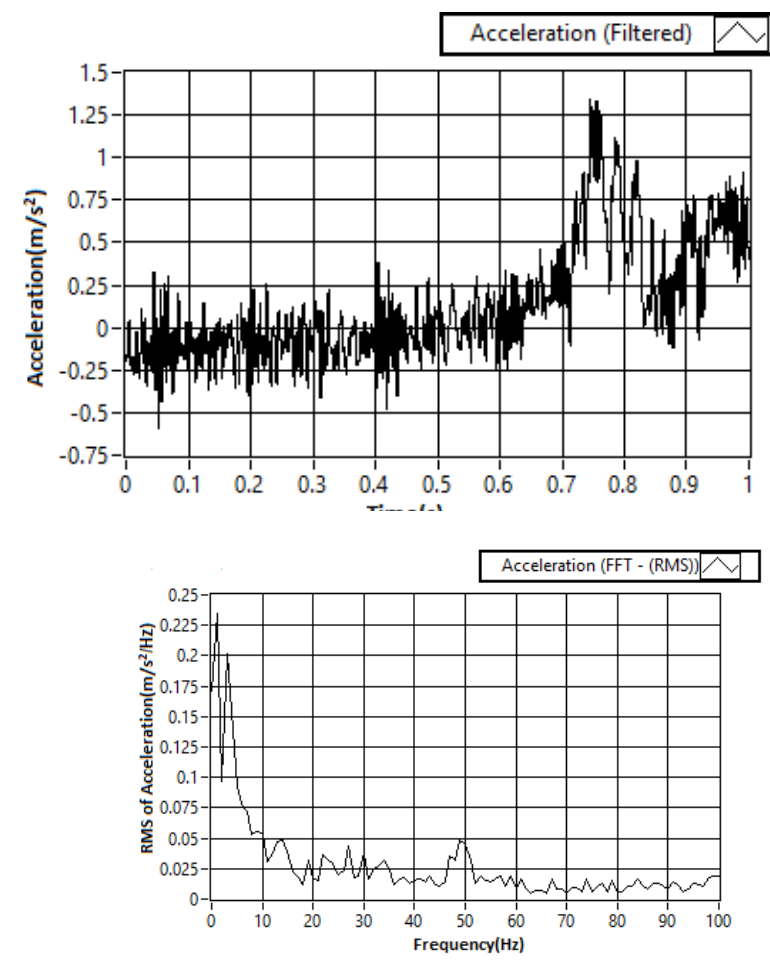

Fig 8.4: Acceleration for 360rpm- $0.1 \mathrm{~mm}$

Fig 8.5: RMS Acceleration for 360rpm-0.1mm

Acceleration plot is used here as a base to compare the results of the experiments conducted before and after installing DVA. In the Fig 8.4, the values change continuously due to the instability and the random irregularities in the surface of the workpiece. FFTs produce the average frequency content of a signal over the entire time that the signal was acquired. Hence, the FFT-RMS plot in Fig 8.5 should also be considered for analysis as it gives the average energy at each frequency line.

\section{9. $\quad$ Results \& Discussions}

Similar plots shown the trend of acceleration fluctuation for different machining settings and conditions are recorded, saved and compared in Table 9.1. Since vibration energy is found 
by considering all the signals in the measurement range of the spectrum and highest acceleration is achieved by one signal at only one point of time, RMS better explains the vibration pattern and characteristics (Fig 9.1).

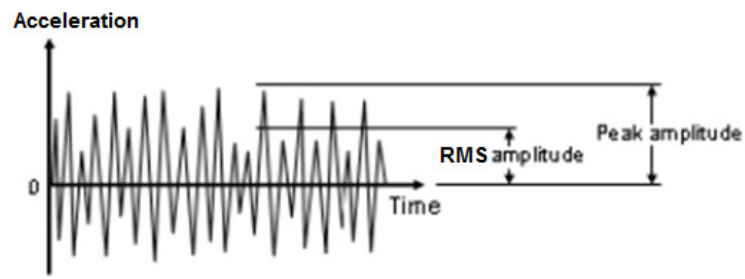

Fig 9.1: RMS amplitude and Peak amplitude

Also by considering the percentage reduction values achieved in maximum amplitude values and the RMS values, a very high value of percentage reduction for amplitude values $(80.46 \%)$ is also evident for the lower reliability of the vibration amplitude values than that of the RMS values $(36.41 \%)$ which is relatively low and considerable. There are several factors that play an important role in causing randomness in the amplitude and frequency of the parameters such as vibration modes, mode shapes, stability issues that determine the working region upto which stability can be maintained.

By plotting all the RMS values for each of the 3 values of spindle speed with 3 levels of depth of cut each, the trend followed by all the three plots looks almost the same (Fig 9.2). The difference between the RMS values before and after using SMA-DVA remains low in both the lower level of depth of cut $(0.1 \mathrm{~mm})$ and higher level of depth of cut $(0.3 \mathrm{~mm})$, but it is maximum for the medium value $(0.2 \mathrm{~mm})$. Since this trend is exhibited in all the 3 plots (a), (b) and (c), this cannot be included in the category of chance cause variations. This variation is due to an assignable cause.

\begin{tabular}{|c|c|c|c|c|c|c|c|}
\hline \multirow{2}{*}{$\begin{array}{l}\text { Speed } \\
(\mathrm{rpm})\end{array}$} & \multirow{2}{*}{$\begin{array}{l}\text { Depth } \\
\text { of cut } \\
(\mathrm{mm})\end{array}$} & \multicolumn{2}{|c|}{$\begin{array}{c}\text { Amplitude of } \\
\text { vibration }\end{array}$} & \multicolumn{2}{|c|}{$\begin{array}{c}\text { RMS value of } \\
\text { vibration acceleration }\end{array}$} & \multicolumn{2}{|c|}{$\begin{array}{l}\text { \% reduction after } \\
\text { installing SMA- }\end{array}$} \\
\hline & & $\begin{array}{l}\text { Without } \\
\text { DVA }\end{array}$ & $\begin{array}{l}\text { With } \\
\text { DVA }\end{array}$ & $\begin{array}{l}\text { Without } \\
\text { DVA }\end{array}$ & $\begin{array}{l}\text { With } \\
\text { DVA }\end{array}$ & $\begin{array}{c}\ln \\
\text { amplitud }\end{array}$ & $\begin{array}{c}\text { In } \\
\text { RMS }\end{array}$ \\
\hline \multirow{3}{*}{360} & 0.1 & 4.1945 & 1.3430 & 0.5945 & 0.5563 & 67.98 & 6.43 \\
\hline & 0.2 & 2.0628 & 0.2690 & 0.5349 & 0.2225 & 86.95 & 58.39 \\
\hline & 0.3 & 3.9231 & 1.7625 & 0.7602 & 0.6438 & 55.07 & 15.32 \\
\hline \multirow{3}{*}{580} & 0.1 & 5.1709 & 0.8392 & 0.7501 & 0.5000 & 83.77 & 33.34 \\
\hline & 0.2 & 6.0402 & 0.8407 & 0.8355 & 0.4375 & 86.08 & 47.63 \\
\hline & 0.3 & 5.4090 & 1.0444 & 0.9539 & 0.5750 & 80.69 & 39.71 \\
\hline \multirow{3}{*}{800} & 0.1 & 4.5379 & 0.4524 & 0.6490 & 0.3375 & 90.03 & 47.99 \\
\hline & 0.2 & 11.9979 & 0.4546 & 0.8374 & 0.3063 & 96.21 & 63.43 \\
\hline & 0.3 & 6.6451 & 1.5037 & 0.8206 & 0.6938 & 77.37 & 15.46 \\
\hline
\end{tabular}

Table 2. Accounting for Effect of DVA and Comparision

In the plot for $360 \mathrm{rpm}$ in Fig 9.2(a), this effect is severe because of the large change in slope of both the lines at $0.2 \mathrm{~mm}$. This effect is not much clear in the plot for $580 \mathrm{rpm}$ in Fig 
9.2(b) and is moderately active for $800 \mathrm{rpm}$ in Fig 9.2(c). It is known that shifting of the stability curve upwards increases the stable working region.

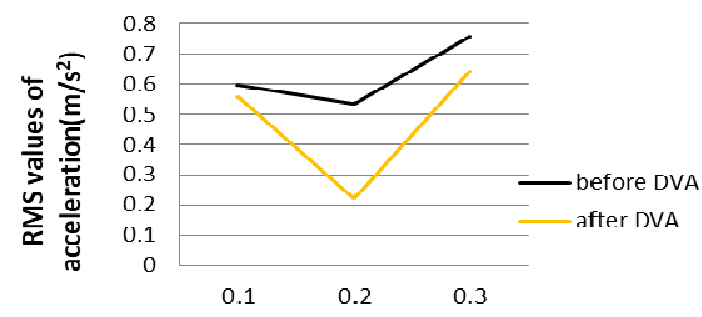

Depth of cut levels (for 360rpm)

(a)

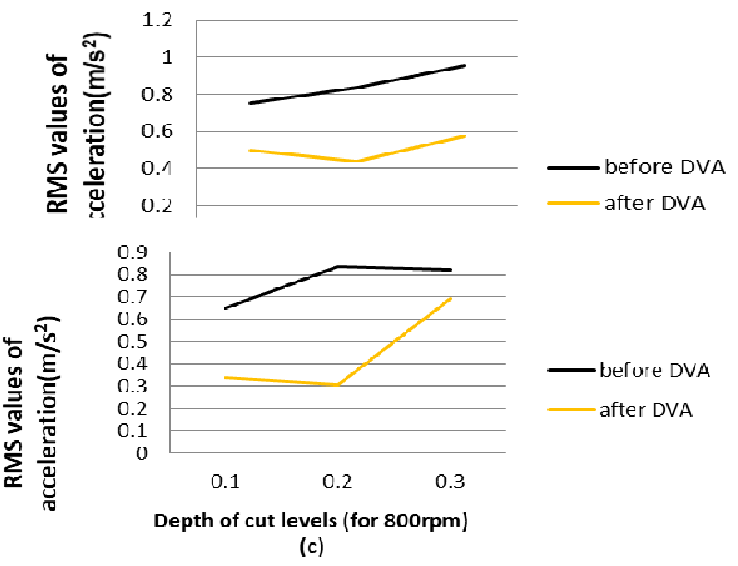

Fig 9.2: RMS values for (a) 360rpm, (b) 580rpm, (c) 800rpm

Maximum amplitude of acceleration values are plotted in a 3-D bar chart using Microsoft Excel for all the nine parameter settings as shown in Fig 9.3. Three dimensional plot for RMS value comparison is as shown in Fig 9.4 and this looks reasonable because of obtaining the expected outcome for increasing depth of cut values.

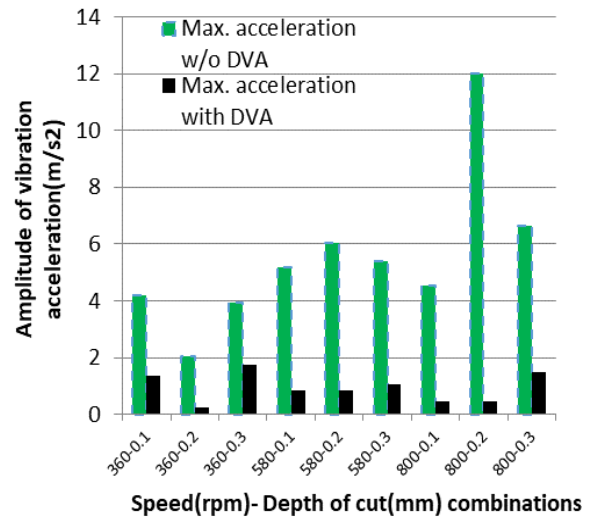


Fig 9.3: Comparison of amplitude

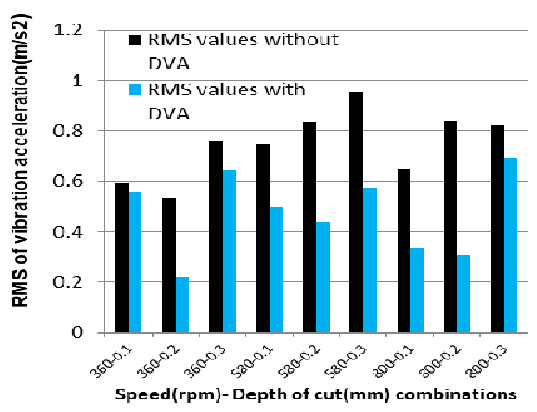

Fig 9.4: Comparison of RMS Acceleration

The variation between before and after DVA values is due to installation of the DVA and the variation among the 9 combinations either with DVA or without DVA is due to the achievement of natural frequency in between experimentation at random moments which may be the reason for the peak of $11.998 \mathrm{~m} / \mathrm{s}^{2}$ for the $800 \mathrm{rpm}-0.2 \mathrm{~mm}$ combination achieved before using DVA.

\section{Conclusion}

The experiment has been carried out on lathe bed using LabVIEW software and acceleration, frequency and displacement responses have been recorded in the form of graphs and tables. From the obtained results, the specifications of the SMA wire are calculated. The SMA wire is then incorporated in the form of a spring component in the DVA. Instead of separately designing a current controller, it is made as part of the block diagram in LabVIEW and by manually changing the current passed through the wire. Accordingly, the properties of the SMA wire are adjusted to the vibration conditions. The percentage reduction of vibration after introduction of DVA setup is also recorded. From the average percentage reduction values of RMS obtained by the SMA-DVA, it is inferred that the vibration in the lathe tool post has decreased considerably thus proving the fabricated DVA to be effective.

\section{References}

[1] Balla Srinivasa Prasad and Prakash Babu. Correlation between vibration amplitude and tool wear in turning: Numerical and experimental analysis. Engineering Science and Technology, (2016). 
[2] Cheung.Y.L, Wong.W.O, and Cheng.L. A subsystem approach for analysis of dynamic vibration absorbers suppressing broadband vibration. Journal of Sound and Vibration(2014).

[3] DeBra DB. Vibration Isolation of Precision Machine Tools and Instruments. Ann CIRP (1992); 41:711-8.

[4] García Plaza.E and Núñez López.P.J. Surface roughness monitoring by singular spectrum analysis of vibration signals. Mechanical Systems and Signal Processing(2016).

[5] Haifeng Ma, Jianhua Wu, Liuqing Yang and Zhenhua Xiong. Active chatter suppression with displacement-only measurement in turning process. Journal of sound and vibration 401(2017) 255267

[6] Jokin Munoa, Xavier Beudaert, Kaan Erkorkmaz, Alex Iglesias, Asier Barrios and Mikel Zatarain. Active suppression of structural chatter vibrations using machine drives and accelerometers.CIRP Annals-Manufacturing Technology(2015).

[7] Linya Liu and Wenjie Shao. Design and Dynamic Response Analysis of Rail with Constrained Damped Dynamic Vibration Absorber. Procedia engineering 15(2011) 4983-4987.

[8] Machado G and Lagoudas C. Nonlinear dynamics of a SMA Passive Vibration Damping Device. Smart Structures and Materials. Proc.Of SPIE Vol. 6169 61690X-2 (2006).

[9] Moradi H, Vossoughi G, Behzad M, and Movahhedy R. Vibration absorber design to suppress regenerative chatter in nonlinear milling process: Application for machining of cantilever plates. Applied Mathematical Modeling (2014).

[10] Senthilkumar M, "Active vibration absorbers in machine tools using shape memory alloys", Journal of CMTI, Vol.5, No.5, 2006, pp.16-19, 2006.

[11] Senthilkumar M, Rajkumar and Shyam Kirthi, "Shape Memory Alloy Based Actively Tuned Undamped Mass Absorber", International Journal of Manufacturing,Materials, and Mechanical Engineering,Vol.2(1), 2012,66-74.

[12] Senthilkumar M, "Analysis of smart wing using shape memory alloy", International journal of aerodynamics, Vol.2, No.1, 2012, pp.22-35. [ISSN: 1743-5455]

[13] Senthilkumar M, Yuvaraja M and Metin KOK, "Fault diagnosis of centrifugal pump and vibration control using shape memory alloy based ATDVA", Applied Mechanics and Materials, Vol. 787, 2015, pp. 927-931

[14] Senthilkumar Mouleeswaran, Yuvaraja Mani, Keerthivasan P and Jagadeesh V, 'Vibration control of small horizontal axis wind turbine blade with shape memory alloy", Smart Structures Systems, Vol. 21, No. 3 (2018) pp.257-262

[15] Senthilkumar M, Vasundhara MG and Rohit Adaikala Raj, " A study on tunable vibration based energy harvester using shape memory effect, National journal of technology, Vol.15, No.3, Sep. 2019, pp. 71-74

[16] Senthilkumar M, Vasundhara MG and Kalavathi GK 2018, 'Electromechanical analytical model of shape memory alloy based tunable cantilevered piezoelectric energy harvester', International Journal of Mechanics and Materials in Design, vol. 15, no. 3, pp. 611-627.

[17] Shariat S, Meng, Mahmud S, Wu, Bakhtiari, Zhang, Motazedian, Yang, Rio and Nam, Liu. Functionally graded shape memory alloys: Design, fabrication and experimental evaluation. Materials and Design 124 (2017) 225-237.

[18] Sriram L, Sriram Prabhu N, Rajkumar V and Senthilkumar M, "Tuned Vibration Absorber using shape memory alloy", Annual research journal, Vol.1, 2011, pp.65-70.

[19] Tavakolpour Saleh A.R and Mailah.M. Control of resonance phenomenon in flexible structures via active support. Journal of Sound and Vibration(2012).

[20] Vasundhara MG, Senthilkumar M and Kalavathi GK 2019, 'A Distributed Parametric Model of Shape Memory Alloy based Resonant Frequency Tunable Cantilevered PZT Energy Harvester with tip mass', ISSS Journal of Micro and Smart Systems, vol. 8, no. 1, pp. 13-24. 